\title{
La literacidad en adultos con baja o nula escolarización. Entrevista a María del Carmen Lorenzatti
}

Mireia Sala Bertran, Universitat Autònoma de Barcelona

Barcelona, España

Entrevista recibida 2 de noviembre, versión final recibida 6 de noviembre de 2013

La entrevista se dibuja en torno a la tesis doctoral de María del Carmen Lorenzatti y a los resultados obtenidos. Su investigación es de corte etnográfico y se sirve de los Nuevos Estudios de Literacidad y la Teoría de la Actividad Humana para descubrir qué saberes cotidianos sociales tienen jóvenes y adultos de nula o baja escolaridad y cómo se vinculan a través de la cultura escrita. El estudio se centra, en concreto, en dos personas: Marta Graciela y Antonio. Cobran importancia conceptos como el de literacidad y su enfoque multimodal y mediación, así como las prácticas escolares y el uso social de la literacidad.

Entrevistadora: La literacidad es social. ¿Lo podría explicar brevemente?

Lorenzatti: La literacidad es social porque los sujetos usamos o desarrollamos la oralidad y la escritura en el marco de distintas acciones con propósitos comunicativos diversos, en diferentes espacios sociales, instituciones sociales, siempre junto a otros, para otros, con otras personas. Las acciones de literacidad suceden en el marco de prácticas más amplias y se encuentran atravesadas por las condiciones políticas, institucionales y sociales de estas prácticas.

En una investigación realizada con adultos de nula/baja escolaridad observé que poseen conocimientos sobre el uso social de la lengua escrita en contextos cotidianos y han aprendido formas de interpretar textos y hacer uso de la escritura en los múltiples contextos sociales - religioso, familiar, laboral, entre otros - a partir del desarrollo de sus actividades. Se trata de prácticas que se dan en un entorno social junto a otras personas y que van más allá de las habilidades individuales, no se trata de aptitudes personales, sino de significados socialmente construidos.

La literacidad es social también porque las personas tienen conocimiento sobre las consecuencias sociales y legales de la escritura y tienen percepciones sobre sí mismos como lectores y escritores.

Entrevistadora: ¿Qué aporta el enfoque multimodal a la literacidad?

Lorenzatti: El concepto de multimodalidad de Kress (2003) me permitió comprender de qué manera los adultos de nula/baja escolaridad construyeron sentido y significado a la realidad a lo largo de toda su vida. No sólo se aprende a leer y escribir con otros sino que esa lectura del mundo, siguiendo la palabra de Paulo Freire, ocurre a partir de distintos modos. Los números, la música, el gesto, los gráficos, los diseños de las distintas envolturas de los productos comerciales son diferentes modos representativos para 
interpretar la realidad y los textos con los que los adultos interactúan cotidianamente en las condiciones sociales concretas de su vida. En este marco la escritura es un modo más, pero no el único válido.

Voy a dar un ejemplo que clarifique lo expresado. La señora Marta Graciela nació en un paraje rural de un estado boliviano donde era común que las mujeres no fueran a la escuela. Sus hermanos varones leen y escriben, asistieron a la escuela en su país cuando eran niños. Ella no lo hizo y tuvo que hacer uso de otros modos representativos, tales como el discurso, la imagen, el gesto, de acuerdo a sus necesidades y a los requerimientos que fue sorteando en su historia de vida. Pude observar que los modos representativos más utilizados por Marta Graciela para ingresar y circular en los distintos espacios sociales visitados (iglesia, instituciones estatales, escuela, su casa) son la imagen gráfica y el lenguaje verbal. La forma, la fragancia, el color y el tamaño. En una de las visitas a un supermercado, frente a la góndola de productos de belleza, la señora eligió dos jabones, tomó uno en cada mano y me preguntó acerca de la diferencia entre ambos. No era fácil determinar dada la similitud entre ellos. Demoré en contestar y Marta Graciela entonces me fue dando pistas para identificar los jabones: me orientó para distinguirlos. En primer lugar tuvo en cuenta los colores, aunque el diseño e inscripción eran casi iguales. A este registro le agregó luego otro atributo del producto que le ayudó a completar el significado: el olor. En efecto, los jabones tenían diferentes fragancias. Ella hizo explícita la relación entre estos modos de apropiación de significados y conocimientos. Recuerdo que me dijo: "Claro ijasí se aprende!!"

Otro aporte importante de este enfoque es el reconocimiento de los distintos medios de diseminación del mensaje y en mi investigación pude observar cómo los adultos conocen lo que sucede en el mundo a través de la televisión y la radio. También señalo que no se trata de personas que viven aisladas "por no leer y escribir convencionalmente" sino que se comunican a través de teléfonos tanto fijos como móviles, conocen el valor y la función de las computadoras, de los emails y de internet.

Entrevistadora: Parece que la perspectiva multimodal de la literacidad constituye una ruptura hacia la estigmatización de la escritura como único modo de comprensión del mundo. ¿Qué ventajas puede suponer esto?

Lorenzatti: La potencialidad de la multimodalidad permite ampliar el horizonte analítico y de esta manera derribar los estigmas hacia los adultos de baja o nula escolaridad; también debo decir que rompe con la dicotomía analfabeto/alfabetizado que está aún presente en varios discursos pedagógicos, ministeriales y de otros actores sociales. Esta perspectiva muestra que las letras no son portadoras unívocas de significado sino que es el objeto físico - el color, el dibujo, las letras, la fragancia - lo que de manera conjunta posibilita la apropiación de conocimientos. Es la relación entre estos atributos lo que orienta la significación del texto.

Entrevistadora: En su estudio se centra en "lo cotidiano". ¿Por qué?

Lorenzatti: Trabajar desde un enfoque contextual y relacional permite buscar las huellas de los distintos contextos que atraviesan las prácticas, en este caso, las de literacidad. Para 
esto me sumergí en la vida cotidiana de los dos sujetos de nula escolaridad. Mi intención era comprender de qué manera cada uno de ellos, a partir de sus trayectorias diferentes pero con ciertos nudos históricos comunes, pudieron entretejer un proyecto de vida con un uso restringido del sistema de escritura.

El concepto de vida cotidiana y conocimiento cotidiano (Heller, 1977) abre la mirada a las acciones de los sujetos en el mundo social y ayuda a comprender que cada sujeto necesita aprender a "usar" las cosas, apropiarse del lenguaje y las costumbres. Es este "pequeño mundo", es la clase o grupo social el espacio generador de sentido en la vida de los sujetos y sus aprendizajes. Gee (1996) expresa que la manera de leer cierto tipo de texto es sólo adquirido a partir de la pertenencia a un grupo social. Estudiar lo cotidiano, a partir del enfoque etnográfico, permite comprender lo que sucede in situ con las prácticas de literacidad y en este sentido pude observar que las personas que no leen y escriben de manera convencional poseen conocimientos construidos en contextos cotidianos; que ellos han aprendido en múltiples contextos sociales donde desarrollan sus actividades (religioso, familiar, laboral, entre otros) las diversas formas de interpretar textos y hacer uso de la escritura. Por ejemplo, he reconocido los conocimientos de una una serie de "papeles", documentos, formularios, tarjetas, cartas, almanaques, documentos religiosos, cancioneros, boletas de impuestos que conforman su "pequeño mundo". A su vez, lo cotidiano de estas personas incluye acciones en instituciones que demandan otras prácticas, que exigen otros conocimientos donde siempre está involucrada la literacidad.

Entrevistadora: La mediación — simbólica y humana - se dibuja como ayuda en la apropiación de conocimientos. ¿De qué tipo de ayuda se trata? ¿En qué sentido es una ayuda? ¿Qué puede aportar este concepto en contextos de adultos con baja o nula escolaridad?

Lorenzatti: Cuando se habla de literacidad y de multimodalidad se reconoce la presencia de la mediación. Entiendo que se trata de una ayuda porque se trata de herramientas que ayudan a la construcción de significado. Por ejemplo, en el caso del espacio social religioso, la señora tenía varios interlocutores que realizaban la mediación de diversas maneras y en escalas distintas: el pastor, la líder de la red evangélica y las vecinas que son fieles y amigas de Marta Graciela. Todos predican a grupos de personas y comparten con ellos la palabra de la Biblia, la palabra divina. Es en este ejemplo donde se puede ver que la interacción con otros para construir significados es una actividad cotidiana común. Por eso hablo de un proceso de multimodalidad mediada donde el acceso a la literacidad está dado por la interrelación de modos representativos, los medios de diseminación del mensaje y los instrumentos mediadores que intervienen en cada acción.

Entrevistadora: En su estudio constata una caracterización del analfabeto adulto totalmente diferente a la caracterización socialmente aceptada. ¿Podría explicársela al lector? ¿A qué se podría deber esta diferenciación?

Lorenzatti: Uno de los objetivos de mi investigación fue precisamente mostrar que los adultos que por condiciones sociales y políticas no pudieron acceder a la escolaridad son sujetos sociales con conocimientos, con participación social y política, con posibilidades de 
argumentar, explicar, razonar. Estamos acostumbrados a escuchar que este grupo de personas no participan, no saben, no opinan porque "no saben leer y escribir".

A partir del abordaje etnográfico, que demandan los estudios de literacidad, encontré evidencias empíricas para cuestionar esta mirada. Observé cómo los adultos estudiados luchan por ejercer sus derechos y construyen un proyecto de vida, que implica una mirada al futuro. Señalo especialmente la condición activa de ambos adultos investigados porque pueden programar, anticipar situaciones, realizar conjeturas, desarrollar trámites... en definitiva "moverse" en el mundo social. En cada una de estas acciones está presente la literacidad que a su vez, y en función de los propósitos de las personas, va ocupando diferentes lugares. La diferencia entre los postulados de mi investigación y el discurso oficial sobre la problemática del analfabetismo está dada por el posicionamiento político frente al sujeto que no fue a la escuela. Mis estudios parten de considerarlo como un sujeto social y político que no fue a la escuela porque nació en condiciones sociales adversas y sus procesos educativos transcurrieron en otros espacios sociales. Nuestros trabajos con maestros y/o alfabetizadores apuntan a reconocer las potencialidades y conocimientos construidos a lo largo de las trayectorias laborales, familiares y de participación social de los adultos. De ninguna manera avalamos la mirada desde las carencias de los sujetos.

Entrevistadora: Habla de partir de los conocimientos de los alumnos y, desde aquí, organizar y llevar a cabo prácticas que contemplen el uso social de la lengua escrita. ¿Cree que los planteamientos escolares difieren mucho del uso social de la literacidad que los adultos con nula o baja escolarización necesitan?

Lorenzatti: Las investigaciones que realizamos desde hace varios años en escuelas o centros educativos de la ciudad de Córdoba (Argentina) nos muestran que hay un olvido del uso social de la lengua escrita dentro del aula para jóvenes y adultos. En general el eje de la enseñanza está puesto en la lectura y escritura, específicamente en ésta enfatizando en el aprendizaje del código como si la alfabetización estuviera desprovista de contenidos sociales. Es decir, la unión grafema-fonema excluye, desde esta visión, todo tipo de significación de la realidad. Sólo importa la decodificación de la palabra escrita. Ésta es la práctica que se considera neutral y apolítica.

Pude observar a Marta Graciela sentada en un banco deletreando bra-bre-bri cuando por fuera de este espacio escolar discutía y peleaba para conseguir mejores condiciones de vida y podía leer carteles de instituciones, de calles, remedios, productos de belleza, entre otros. Estas cuestiones quedan afuera de la escuela y se remite a un dictado o copia de palabras en el pizarrón.

Entrevistadora: Conocimiento y práctica. El primero es un proceso vital ligado al segundo. ¿Cree que existe una dicotomía teoría-práctica tal como la plantea Antonio, uno de los sujetos analizados en su tesis?

Lorenzatti: Maria Saleme, mi maestra, decía que el conocimiento del sujeto adulto está dentro y con el sujeto, forma parte de su dinámica vital. Y esto me parece fundamental a la hora de pensar cómo trabajar con adultos de nula/baja escolaridad. Antonio recupera lo que conoce, su propia práctica, no conoce otra cosa. No tuvo oportunidad de estudiar, por 
ejemplo, el circuito eléctrico. Nadie le explicó los fundamentos desde las distintas disciplinas científicas o escolares, sólo le enseñaron a trabajar con los cables en la fábrica. Por esta razón él reafirma sus conocimientos pragmáticos y desde allí se diferencia de los ingenieros jovencitos que recién ingresaban a trabajar.

En términos académicos no es una cuestión dicotómica, todo lo contrario: es una relación dialéctica teoría y práctica. Este posicionamiento es básico en educación de jóvenes y adultos porque es una manera de reconocer todos los conocimientos construidos a partir de la participación en los distintos espacios sociales recorridos. Pero no se trata de recuperar solamente sino de avanzar sobre ellos. Es tarea de la escuela hacer el salto epistemológico que le permita al sujeto conocer los fundamentos teóricos de sus decisiones, y fundamentar (valga el juego de palabras) su proyecto de vida.

Entrevistadora: ¿De qué modo cree que su estudio puede ser útil para los maestros que se dedican a la enseñanza con personas adultas con nula o baja escolaridad?

Lorenzatti: Con este estudio pretendo ayudar a los maestros a preguntarse sobre qué, quiénes y de qué manera se lee y se escribe en las clases diarias, cómo ingresa el mundo social, cuántos de los recursos de cultura escrita que irrumpen cotidianamente la vida de los jóvenes y adultos son usados como dispositivos de la enseñanza en estos espacios. Recupero los dichos de los adultos: "No lo puedo" (dice Marta Graciela) y "está duro el pato para pelar" (insiste Antonio) porque van consolidando percepciones sobre sus posibilidades individuales de apropiación de la cultura escrita en el aula.

La apropiación de la lengua escrita no es un problema cognitivo individual de las personas. Esta delegación de responsabilidad en los adultos esconde la responsabilidad de las estructuras de poder y de las instituciones sobre la literacidad. Esta es la versión remedial y compensatoria de la educación de adultos que contribuye en gran parte para que sujetos como los que estudié en esta investigación se consideren "analfabetos". Es mi intención debatir sobre esto y decir que partir de lo que los alumnos saben implica un reconocimiento de ellos como seres humanos, y se hace imperioso desde ese lugar organizar, planificar e implementar prácticas que incluyan el uso social de la lengua escrita.

De esta manera enseñar a leer y escribir a las personas jóvenes y adultas es una cuestión de respeto a sus procesos sociales de apropiación de conocimientos, sus modos históricos de apropiación en los distintos espacios sociales donde se desempeñan cotidianamente.

Entrevistadora: Muchas gracias por su tiempo y sus valiosas aportaciones.

\section{Referencias bibliográficas}

Gee, P. J. (1996). Social linguistics and literacies. Ideology in discourses (Second Edition). New York: RoutledgeFalmer.

Heller, A. (1977). Sociología de la vida cotidiana. Barcelona: Ediciones Península. Kress, G. (2003). Literacy in the new media age. London: Routledge. 
Referencias de la entrevistadora:

Mireia Sala Bertran es graduada en Filología Catalana por la Universidad de Barcelona y ha cursado el Máster en Investigación en Didáctica de la Lengua y la Literatura en la Universidad Autónoma de Barcelona, donde ha iniciado el programa de Doctorado en Educación. Trabaja como profesora en distintas áreas.

Email: m.salabertran@gmail.com

Para citar este artículo:

Sala Bertran, M. (2013). La literacidad en adultos con baja o nula escolarización. Entrevista a María del Carmen Lorenzatti. Bellaterra Journal of Teaching \& Learning Language \& Literature, 6(4), 81-85. 